\title{
Early prognosis in coma after cardiac arrest: a prospective clinical, electrophysiological, and biochemical study of 60 patients
}

\author{
C Bassetti, Fulvio Bomio, Johannes Mathis, Christian W Hess
}

\begin{abstract}
Background-The univariate study of clinical, electrophysiological, or biochemical variables has been shown to predict the outcome in postanoxic coma in about $50 \%$ of patients for each type of variable. Previous studies did not, however, consider the prognostic accuracy of a multivariate approach.

Methods-Sixty patients in coma for more than six hours after cardiac arrest were prospectively examined by means of repeated clinical examinations (including Glasgow coma score (GCS)), EEG, and medianus nerve somatosensory evoked potentials (SEPs). In 16 patients, the early concentrations of serum neuron specific enolase and ionised calcium were also measured.
\end{abstract}

Results-Within the first year after cardiac arrest, $20 \%$ of patients made a good neurological recovery; $80 \%$ remained in a vegetative state or died. Clinical examination correctly predicted outcome in $58 \%$ of patients, SEP in $59 \%$, and EEG in $41 \%$. The combination of clinical examination, SEP, and EEG raised the percentage of correct predictions to $82 \%$, without false pessimistic predictions. Concentrations of serum neuron specific enolase and ionised calcium were of no additional prognostic help. Multivariate regression analysis identified the association of GCS $<8$ at 48 hours with abnormal or absent early cortical SEPs as highly predictive of a bad outcome (risk $=97 \%, 95 \%$ confidence interval $=86-99 \%)$.

Conclusion-The combination of GCS at 48 hours, SEP, and if these are nonconclusive, EEG, permits a more reliable prediction of outcome in postanoxic coma than clinical examination alone.

Department of

$(尹$ Neurol Neurosurg Psychiatry 1996;61:610-615)

Neurology

C Bassetti

CW Hess

Department of

Medicine, University

Hospital (Inselspital)

Bern, Switzerland

F Bomio

Correspondence to:

Dr C Bassetti, Department

of Neurology, University

of Neurology, University

Bern, Switzerland.

Received 29 January 1996 and in revised form

13 August 1996

Accepted 19 August 1996 estimate, neuronal damage must be assessed indirectly by exploring cerebral functions and evaluating their pattern of recovery over time. In general, the longer the delay in recovery of function the worse the prognosis. Due to the greater vulnerability of the cerebral cortex to hypoxia than the brainstem, recovery usually occurs in a caudorostral sequence, ${ }^{5}$ and the maximal recovery time still compatible with a good outcome depends on the neurological function being considered. Several studies have shown that the duration and depth of coma are good predictors of outcome. ${ }^{3567}$ The absence of brainstem reflexes for more than six to 24 hours after cardiopulmonary resuscitation, ${ }^{3589}$ absent motor responses to pain for more than one or two days, ${ }^{371011}$ the persistence of a Glasgow coma score (GCS) $<5$ for more than two or three days, ${ }^{67}$ and of a GCS $<8$ for more than one week ${ }^{36}$ all herald a poor outcome. However, clinical prognostication within the first few days after cardiopulmonary resuscitation is afflicted with incontestable limitations. Firstly, there is a risk of false pessimistic predictions, ${ }^{12}$ which may be as high as $5 \%$ to $10 \% .{ }^{13}{ }^{14}$ Secondly, brainstem functions normalise in most patients within a few hours and accurate prediction of outcome in these patients is not possible within the first two days after cardiopulmonary resuscitation, as even a GCS of 3 is compatible with a good outcome. ${ }^{371516}$ Thirdly, the accuracy of clinical parameters is limited in intubated patients who often need muscle relaxation and sedation. For these reasons, an intense search for electrophysiological and biochemical criteria for prognosis in postanoxic coma has been undertaken. The absence of continuous EEG activity for more than eight hours after cardiopulmonary resuscitation, ${ }^{5}$ the presence of a periodic or "burst suppression" EEG, ${ }^{17-19}$ and the absence of early cortical SEPs ${ }^{160-22}$ in the first two to three days have been shown to be reliable predictors of a bad outcome. More recently, biochemical parameters such as serum glucose at admission, ${ }^{2}$ serum ionised calcium, ${ }^{23} \mathrm{CSF}$ creatine kinase, ${ }^{22}{ }^{24} \mathrm{CSF}$ lactate, ${ }^{25}$ and serum neuron specific enolase, ${ }^{26}$ have been suggested as potential "markers" of diffuse cerebral ischaemia. Their prognostic accuracy, however, remains to be confirmed. Despite considerable information about the prognostic accuracy of single parameters alone, the value of a multivariate approach has not yet been determined. Clearly, the combined analysis of, for example, clinical examination, EEG, and SEP has the potential advantage of giving a more complete func- 
tional profile of a patient. To assess whether a multivariate approach provides a better prediction of outcome within the first three days after cardiopulmonary resuscitation, we prospectively studied a consecutive series of patients in postanoxic coma with a standard examination protocol which included repeated clinical examinations, EEG, and SEP, serum ionised calcium, and serum neuron specific enolase.

\section{Patients and methods}

We studied a series of 60 consecutive patients after cardiac arrest and cardiopulmonary resuscitation who remained comatose, as defined elsewhere, ${ }^{3}$ for more than six hours. The average age was 62 years, ranging from 19 to 86 years, and 49 were men. Patients with craniocerebral trauma, pre-existing intracranial lesions, or drug intoxication were excluded. All patients were initially intubated, most received slight hyperventilation, intravenous nutrition, and slight sedation with midazolam or morphine. Intensive care treatment was guaranteed in all patients for at least the first three days after cardiopulmonary resuscitation.

Repeated clinical examination was performed in each patient at regular intervals between six to 12 hours, at 24 hours, at 48 hours, and at one week after cardiopulmonary resuscitation. All clinical assessments were performed by two of us (CB, FB). Glasgow coma score (best 15, worst 3), corneal, pupillar, and oculocephalic brainstem reflexes, the presence of spontaneous flexor ("decortication") or extensor ("decerebration") posturing, and myoclonic or epileptic phenomena were noted.

Electrophysiological studies were carried out within the first three days after cardiopulmonary resuscitation in all but four patients; EEG and SEP were always recorded 12 hours or more after cardiopulmonary resuscitation, as even an isoelectric EEG before this interval does not exclude full recovery. ${ }^{27}$ In 48 patients both EEG and SEPs were recorded within 24 hours of each other. An eight channel EEG was recorded in 59 patients for at least $30 \mathrm{~min}$ utes, using the international 10-20 system and including testing of the reactivity to acoustic, painful, and photic stimulation. Recordings were classified by a visual analysis in a five grade scale of increasing severity (table $1^{18}$ ). SEPs were obtained from 56 patients by electrical stimulation of the median nerve at the wrist. ${ }^{28}$ The central conduction time and the P25/N20 amplitude ratio ${ }^{20}$ of SEPs were defined as abnormal when exceeding control data from healthy subjects in our laboratory by more than $2.5 \mathrm{SD}$. Results of the SEP were classified in three grades of increasing severity (table 1). Clinical, EEG, and SEPs findings were classified in three prognostic groups (favourable; uncertain; unfavourable) according to currently suggested prognostic criteria (see above and table 2 ). Only very selective criteria for unfavourable outcome were chosen to avoid false pessimistic predictions.
Table 1 Grading of EEG and medianus somatosensory evoked potentials (SEPs)

\begin{tabular}{|c|c|}
\hline & $E E G$ \\
\hline Grade I & Dominant normally distributed $\alpha$ activity, reactive \\
\hline Grade II & Dominant $\theta-\delta$ activity, reactive \\
\hline Grade III & $\begin{array}{l}\delta-\theta \text { activity without } \alpha \text { activity } \\
\text { Reactive or non-reactive }\end{array}$ \\
\hline Grade IV* & " $\alpha$ or $\theta$ coma", non-reactive \\
\hline Grade IV & Burst suppression activity \\
\hline & Low voltage $\delta$ activity, non-reactive \\
\hline & $\begin{array}{l}\text { Periodic general phenomena with isoelectric } \\
\text { intervals }\end{array}$ \\
\hline Grade V & $\begin{array}{l}\text { Very low voltage EEG } \\
\text { Isoelelectric EEG }\end{array}$ \\
\hline & $S E P$ \\
\hline Grade I & $\begin{array}{l}\text { Normal N20/P25 response bilaterally } \\
\text { (normal amplitude + normal central conduction } \\
\text { time) }\end{array}$ \\
\hline Grade II & $\begin{array}{l}\text { Abnormal N20/P2 } 25 \text { response unilaterally or } \\
\text { bilaterally (amplitude reduction }>50 \% \text { or } \\
\text { CCT }>7.2 \mathrm{~ms} \text {, or both) }\end{array}$ \\
\hline Grade III & Absent N20/P25 bilaterally \\
\hline
\end{tabular}

Biochemical studies were carried out in 16 patients. Serum neuron specific enolase concentrations were determined in heparinised blood 12 and 24 hours after cardiopulmonary resuscitation. Concentrations in serum were measured by a commercially available radioimmunoassay (Pharmacia-PDF-Sweden). The concentration of serum neuron specific enolase measured in healthy subjects in our laboratory is $<20 \mathrm{~m} \mathrm{~mol} / 1$. Ionised calcium, total calcium concentrations, and $\mathrm{pH}$ were determined in an arterial sample of heparinised blood four and 12 hours after cardiopulmonary resuscitation. Measurements were performed with a calcium selective electrode and corrected for a $\mathrm{pH}$ of $7 \cdot 4$. The normal range of ionised calcium concentrations in healthy subjects in our laboratory is $1 \cdot 20-1 \cdot 30 \mathrm{mmol} / \mathrm{l}$, and for total calcium it is $2 \cdot 10-2 \cdot 50 \mathrm{mmol} / \mathrm{l}$.

Outcome was defined as the best cerebral performance achieved at any follow up time and classified by analogy with the GOS into two groups: (1) good outcome: awakening with reappearance of signs of cognition (Glasgow outcome scale (GOS) 3-5); (2) bad (poor) outcome: persistent vegetative state or death (GOS 1-2). Outcome was evaluated at one, two, and seven days, as well as one month and one year after cardiopulmonary resuscitation. We decided to include patients with a GOS $=3$ in the "good outcome" group because some recovery may occur in this patient group beyond our observation time.

\section{STATISTICAL ANALYSIS}

Predictive values were determined for favourable and unfavourable factors. Favourable predictive values (percentage of patients with the test result whose good outcome was correctly predicted), and unfavourable predictive values (percentage of patients with the test result whose bad outcome was correctly predicted) and their approximate $95 \%$ confidence intervals (95\% CIs) were calculated for clinical, EEG, and SEP parameters. The number (and percentage) of correct and wrong predictions of both good and bad outcome were calculated for clinical examination, EEG, and SEP separately, according to the prognostic criteria shown in table 2 . We decided to use these cri- 
Table 2 Published prognostic criteria of clinical examination, EEG and SEPs in the literature

\begin{tabular}{llll}
\hline & $\begin{array}{l}\text { GCS at 48-72 hours } \\
\text { BR at 6-12 hours }\end{array}$ & EEG grade & SEPs \\
\hline Favourable & $\geqslant 8$ & I-II & Normal \\
Uncertain & and normal BR & III, IV & Abnormal \\
Unfavourable & $\begin{array}{l}5-7 \\
\text { and normal BR }\end{array}$ & $\begin{array}{l}\text { N20/P25 } \\
\text { Absent }\end{array}$ & N20/P25 bilaterally \\
\hline
\end{tabular}

* " $\alpha$ or $\theta$ coma".

GCS = Glasgow coma score; BR = brainstem reflexes (corneal, pupillary, oculocephalic); SEP $=$ medianus somatosensory evoked potentials.

teria because their accuracy has already been proved in several large series of patients (see introduction). The prognostic value of the combination of the three modalities was assessed as follows. A good outcome was predicted if there were (1) no unfavourable findings, and (2) at least one favourable finding on clinical examination, EEG, or SEP. Conversely, a bad outcome was predicted if there were one or more unfavourable findings on clinical examination, EEG, or SEP. The number (and percentage) of correct and wrong predictions of both good and bad outcome were calculated for this multivariate approach. A multivariate logistic regression analysis was used to identify from a series of different parameters (brainstem reflexes at 6-12 hours, GCS at 24 hours, GCS at 48 hours, motor responses at 24 and at 48 hours, EEG, and SEP) the combination which best predicts the outcome. The comparison of patients with good and bad outcome was performed for parametric variables with the unpaired $t$ test, and for non-parametric variables with the Mann-Whitney $U$ test, $\chi^{2}$ test, and comparison of proportions test.

\section{Results}

Of 60 patients in coma for more than six hours after cardiopulmonary resuscitation, $12(20 \%)$ had a good outcome and $48(80 \%)$ had a bad outcome. Five of 12 patients with good outcome remained in coma (GCS < 8) for two or more days after cardiopulmonary resuscitation. However, all but one of the 12 patients

Table 3 Prognostic value of clinical findings, EEG, and SEPs in 60 patients with postanoxic coma

\begin{tabular}{|c|c|c|c|c|}
\hline & \multicolumn{4}{|c|}{ Time after cardiac arrest (h) } \\
\hline & $6-12$ & 24 & 48 & $12-72$ \\
\hline \multicolumn{5}{|c|}{$\begin{array}{l}\text { Predictors of good outcome } \\
\text { st result whose good outcome was correctly predicted) }\end{array}$} \\
\hline \multirow{3}{*}{$\begin{array}{l}3 \text { BR present } \\
\text { GCS } \geqslant 8 \\
\text { Spontaneous eye opening } \\
\text { Favourable EEG (grade I-II) } \\
\text { Favourable SEP (N20/P25 } \\
\text { normal bilaterally) }\end{array}$} & \multirow[t]{3}{*}{$\begin{array}{l}29(28) \\
50(4) \\
17(6)\end{array}$} & \multirow[t]{3}{*}{$\begin{array}{l}33(21) \\
50(8) \\
23(13)\end{array}$} & \multirow[t]{3}{*}{$\begin{array}{l}33(27) \\
78(9) \\
53(15)\end{array}$} & \\
\hline & & & & $40(10)$ \\
\hline & & & & $50(20)$ \\
\hline \multirow{4}{*}{$\begin{array}{l}\text { (percentage of patients with the tes } \\
>1 \mathrm{BR} \text { absent } \\
\text { GCS }<5 \\
\text { Poor motor response } \\
\text { Seizures or myoclonus } \\
\text { Unfavourable EEG (Grade IV-V) } \\
\text { Unfavourable SEP (N20/P25 } \\
\text { absent bilaterally) }\end{array}$} & \multirow{2}{*}{\multicolumn{3}{|c|}{$\begin{array}{l}\text { Predictors of bad outcome } \\
\text { esult whose bad outcome was correctly pr } \\
\begin{array}{lll}100(10) & 100(5) & 100(3) \\
81(27) & 87(31) & 100(20) \\
79(38) & 85(48) & 92(37)\end{array}\end{array}$}} & icted) \\
\hline & & & & \\
\hline & & & & $\begin{array}{r}96(25) \\
100(20)\end{array}$ \\
\hline & & & & $100(23)$ \\
\hline
\end{tabular}

Values are \% with total number of patients in parentheses (95\% CIs are given in the text) $\mathrm{BR}=$ brainstem reflexes (corneal, pupillary, oculocephalic); GCS = Glasgow coma score; SEP = medianus nerve somatosensory evoked potential.

^No or only stereotyped (extensor, flexor) motor response to pain. awakened and reached their best level of function within the first week, and nine patients eventually became independent in daily activities. Thirteen of 60 patients $(22 \%)$ died within the first three days, six of whom were certified brain dead. Within the next month a further 31 patients died, mostly (29/31) without awakening from coma. Four patients remained in a vegetative state for more than one month and died $70,72,89$, and 280 days after cardiopulmonary resuscitation. Table 3 summarises the predictive values of clinical findings, EEG, and SEP.

\section{CLINICAL EXAMINATION}

Only eight of 28 patients with normal brainstem reflexes at 6-12 hours had a good outcome (favourable predictive value $=29 \%$, $95 \%$ CI $13-49 \%)$. On the other hand, all 10 patients in whom two or more brainstem reflexes were absent at 6-12 hours died in coma (unfavourable predictive value $=100 \%$, $69-100 \%$ ). The GCS in the first 24 hours ranged between 3 and 14 in patients with good outcome, and between 3 and 9 in patients with bad outcome. However, seven of nine patients with a GCS $>8$ at 48 hours had a good outcome (favourable predictive values $=78 \%$, 40-97\%), whereas all 20 patients with a GCS < 5 at 48 hours had a bad outcome (unfavourable predictive value $=100 \%$, $83-100 \%$ ). Spontaneous eye opening was often seen within the first 48 hours in patients with both good and bad outcome. Hence, the favourable predictive values of spontaneous eye opening was only $23 \%(5 \%-54 \%)$ at 24 hours, and $53 \%(27-79 \%)$ at 48 hours. Poor motor responses to pain (absent or stereotyped responses) heralded a poor outcome, particularly at 48 hours (favourable predictive value $=92 \%, 78-98 \%$ ). Myoclonic or other epileptic phenomena were seen within the first three days after cardiopulmonary resuscitation in 25 patients, and were limited in eight of them to the periocular region. Twenty four patients had a bad outcome (unfavourable predictive value $=96 \%, \quad 80-100 \%)$. Spontaneous "decerebration" and "decortication" spasms were found in 11 patients including four patients with a good outcome. One patient with good outcome had these up to 34 hours after cardiopulmonary resuscitation.

\section{ELECTROPHYSIOLOGY}

Four of 10 patients with favourable EEG (grade I-II) had a good recovery (favourable predictive value $=40 \%, 12-74 \%$ ). An unfavourable EEG (grade IV-V) was found in $20(34 \%)$ of 59 patients. All 20 patients had a bad outcome (unfavourable predictive value $=100 \%, 83-100 \%)$. Fourteen of 59 patients (24\%) had an " $\alpha$ or $\theta$ coma" EEG (grade IV). In 11 of them cortical SEPs were absent bilaterally and none recovered. In two patients " $\alpha$ coma" was "incomplete" 18 as the EEG activity was either diffusely distributed or intermittently reactive. Both patients had normal SEPs, and one of them had a good recovery. SEPs were obtained in 56 patients. Normal SEPs were recorded in 20 patients, and 10 of 
Table 4 Comparison of patients with good and bad outcome after postanoxic coma

\begin{tabular}{|c|c|c|c|}
\hline & $\begin{array}{l}\text { Good outcome } \\
(n=12)\end{array}$ & $\begin{array}{l}\text { Bad outcome } \\
(n=48)\end{array}$ & $P$ value \\
\hline Age $(y(S D))$ & $64 \cdot 8(12 \cdot 4)$ & $60 \cdot 8(16 \cdot 5)$ & NS \\
\hline \multicolumn{4}{|l|}{$\begin{array}{l}\text { Brainstem reflexes } \\
\text { (at } 6-12 \text { hours, } \mathrm{n}(\%)) \text { : }\end{array}$} \\
\hline All three present & $8(67)$ & $20(48)$ & NS \\
\hline Two or more absent & & $10(24)$ & $<0.05$ \\
\hline \multicolumn{4}{|l|}{$\begin{array}{l}\text { Poor motor responses (no or only } \\
\text { stereotyped responses, } \mathrm{n}(\%) \text { ): }\end{array}$} \\
\hline $\begin{array}{l}\text { At } 6-12 \text { hours } \\
\text { At } 24 \text { hours } \\
\text { At } 48 \text { hours }\end{array}$ & $\begin{array}{l}8(80) \\
7(70) \\
3(25)\end{array}$ & $\begin{array}{l}30(97) \\
39(87) \\
34(92)\end{array}$ & $\begin{array}{l}\text { NS } \\
\text { NS } \\
<0.05\end{array}$ \\
\hline \multicolumn{4}{|l|}{ Spontaneous eye opening (n (\%)): } \\
\hline $\begin{array}{l}\text { At } 6-12 \text { hours } \\
\text { At } 24 \text { hours } \\
\text { At } 48 \text { hours }\end{array}$ & $\begin{array}{l}1(11) \\
3(33) \\
8(67)\end{array}$ & $\begin{array}{r}5(17) \\
10(22) \\
7(18)\end{array}$ & $\begin{array}{l}\text { NS } \\
\text { NS } \\
<0.05\end{array}$ \\
\hline \multicolumn{4}{|l|}{ Glasgow coma scale (score (SD)): } \\
\hline $\begin{array}{l}\text { At } 6-12 \text { hours } \\
\text { At } 24 \text { hours } \\
\text { At } 48 \text { hours }\end{array}$ & $\begin{array}{r}5(3) \\
6(3) \\
10(4)\end{array}$ & $\begin{array}{l}4(2) \\
5(2) \\
5(2)\end{array}$ & $\begin{array}{l}\text { NS } \\
\text { NS } \\
<0.05\end{array}$ \\
\hline \multicolumn{4}{|l|}{$\begin{array}{l}\text { Seizure or myoclonic activity } \\
\text { (within first } 3 \text { days, } n(\%) \text { ) }\end{array}$} \\
\hline \multicolumn{4}{|l|}{ EEG findings ( 59 patients, $\mathrm{n}(\%)$ ): } \\
\hline Favourable or uncertain & $11(100)$ & $28(58)$ & \\
\hline Unfavourable & 0 & $20(42)$ & $<0.05$ \\
\hline \multicolumn{4}{|l|}{ SEP findings ( 56 patients, $\mathrm{n}(\%))$ : } \\
\hline Favourable or uncertain & $11(100)$ & $22(49)$ & \\
\hline Unfavourable & 0 & $23(51)$ & $<0.05$ \\
\hline
\end{tabular}

SEP = medianus nerve somatosensory evoked potentials.

them had a good outcome (favourable predictive value $=50 \%, 30-74 \%$ ). Delayed or low amplitude cortical (N20/P25) evoked potentials were found in 12 patients, and only one of them had a good outcome. Cortical SEPs were absent in 23 patients. All of them had a bad outcome (unfavourable predictive value $=$ $100 \%, 90-100 \%)$. Table 4 shows the comparison of patients with good and bad outcome. The absence of two or more brainstem reflexes at 6-12 hours, poor motor responses at 48 hours, absent spontaneous eye opening at 48 hours, seizure or myoclonic activity, and unfavourable EEG and SEP findings were associated with a bad outcome. There was also a significant difference between patients with good and bad outcome in the GCS at 48 hours, but not in the GCS at 6-12 hours and 24 hours.

\section{BIOCHEMICAL PARAMETERS}

Serum neuron specific enolase concentrations were above normal in seven patients after 12 hours, and in eight patients after 24 hours. The unfavourable predictive values of high serum neuron specific enolase were $86 \%$ at 12 hours and $100 \%$ at 24 hours. Ionised calcium concentrations were below normal in nine patients after four hours, and in 12 patients after 12 hours despite normal concentrations of total calcium. The unfavourable predictive values of low ionised calcium were $89 \%$ at four hours and $83 \%$ at 12 hours.

UNVARIATE AND MULTIVARIATE APPROACH

The percentage of total correct predictions of outcome obtained applying a univariate approach (criteria shown in table 2) was $58 \%$

Table 5 Risk of bad outcome in coma after cardiac arrest (multivariate logistic regression analysis of 60 patients)

\begin{tabular}{lll}
\hline $\begin{array}{l}\text { GCS } \geqslant 8 \text { at } 48 \text { hours } \\
\text { and } \\
\text { SEP normal }\end{array}$ & $\begin{array}{l}\text { GCS }<8 \text { at } 48 \text { hours } \\
\text { or } \\
\text { SEP abnormal or absent }\end{array}$ & $\begin{array}{l}\text { GCS }<8 \text { at } 48 \text { hours } \\
\text { and } \\
S E P \text { abnormal or absent }\end{array}$ \\
\hline $12 \%(95 \%$ CI, $2 \%-46 \%)$ & $68 \%(95 \%$ CI, $47 \%-84 \%)$ & $97 \%(95 \%$ CI, 86\%-99\%) \\
\hline
\end{tabular}

GCS = Glasgow coma score; SEP = medianus nerve somatosensory evoked potential. for the clinical examination, $41 \%$ for the EEG, and $59 \%$ for the SEPs. The combination of three modalities raised the percentage of correct predictions of outcome to $82 \%$. There were no false negative predictions. A correct prediction of bad outcome was possible in 36 of $48(75 \%)$ patients combining clinical examination and SEP alone, a total which was raised by one to $37(77 \%)$ by also considering the EEG. Prediction of a bad outcome was easier in patients who died within the first three days $(92 \%)$ than in those who survived longer $(71 \%)$. Electrophysiological tests were of significant prognostic help in nine $(36 \%)$ of 25 patients in whom prediction based on clinical signs was considered to be uncertain. In addition, unfavourable EEG or SEP findings were found in $23(66 \%)$ of 35 patients with unfavourable clinical signs. Conversely, normal or abnormal biochemical tests were of no additional prognostic help. A correct prediction of good outcome was possible applying the multivariate approach in 11 of 12 patients. There were $39 \%$ false optimistic predictions. A multivariate analysis identified the combination of GCS after 48 hours and SEP as the best predictive combination. The risk of a bad outcome was calculated to be $97 \%$ ( $86 \%$ $99 \%$ ) for patients with a GCS $<8$ and abnormal (or absent) SEP, but only $12 \%(2-46 \%)$ for patients with a GCS > 8 and normal SEPs (table 5).

\section{Discussion}

Coma following resuscitation after cardiac arrest is a serious condition, and a good outcome can be expected in less than $20 \%$ of patients, as shown in this and previous larger series. ${ }^{3}$ Although awakening from coma usually occurs within the first three days after cardiopulmonary resuscitation ${ }^{1025}$ we confirm that recovery after this interval can occur. ${ }^{36}$ Because decisions about limitation or maintenance of intensive care often need to be made within the first few days after cardiopulmonary resuscitation, prognostic criteria in postanoxic coma are needed. In this study we tried to avoid some of the methodological problems of previous studies of prognosis in coma. ${ }^{13}$ Maximal treatment was guaranteed for at least the first three days after cardiopulmonary resuscitation, with the exception of patients in whom the clinical criteria of brain death were satisfied; data were collected prospectively by two observers only; electrophysiological studies were performed within a narrow interval of time from the onset of coma; and $95 \%$ CIs for the suggested predictive model were provided. There are three major findings from our data. Firstly, normal or only mildly abnormal EEG and SEP findings are unreliable predictors of a good outcome. Secondly, currently suggested univariate clinical, EEG, and SEP criteria for prognosis of bad outcome (table 2) are reliable, but identify only about $50 \%$ of the patients who die or remain in a vegetative state. Thirdly, the combination of GCS at 48 hours, SEP, and EEG raises the percentage of accurate prediction of bad outcome to $77 \%$ of the patients. 
PROGNOSIS OF GOOD OUTCOME

Prognosis of good outcome in postanoxic coma is difficult. We confirm that early recovery of brainstem functions and spontaneous eye opening do not necessarily herald a good outcome, in that the cortex may have been damaged to a degree that prevents cognitive recovery. Also, the percentage of false optimistic predictions is high because of a significant extracerebral mortality. ${ }^{79}$ Nevertheless, $78 \%$ of our patients with a GCS $>8$ after 48 hours had a good outcome, a percentage similar to the $82 \%$ reported by Mullie et al in a series of 360 patients. ${ }^{6}$ Conversely, favourable EEG (grade I-II) and normal SEPs were unreliable predictors of good recovery. Our results agree with those of previous series in that $50 \%-60 \%$ of patients with favourable EEG and SEP findings still had a poor outcome. 1821222530 Hence, as long as the patient remains clinically in coma, the absence of relevant EEG and SEP abnormalities should be considered an indispensible condition rather than a "guarantee" for a good outcome. A possible exception is the preservation of long latency (N70) cortical SEPs. ${ }^{16}$

UNIVARIATE PROGNOSIS OF BAD OUTCOME

We confirm that the absence of more than one brainstem reflex for more than 6-12 hours, ${ }^{359}$ a GCS $<5$ at 48 hours or later, ${ }^{67}$ an EEG grade IV-V, ${ }^{17-19}$ and the bilateral absence of cortical SEPs $^{16}$ 20-22 at 12-72 hours after cardiopulmonary resuscitation, all herald a bad outcome without false pessimistic predictions. We also corroborate previous studies that found the following criteria to be unreliable predictors of poor outcome: prolonged absence of a single brainstem reflex, ${ }^{7}$ a low GCS, and poor motor responses within the first 24 hours after cardiopulmonary resuscitation, ${ }^{716}$ spontaneous flexor and extensor posturing, ${ }^{31}$ an " $\alpha$ coma" EEG, ${ }^{182532}$ and abnormal but still detectable cortical SEPs. Poor motor responses to pain at 48-72 hours ${ }^{3} 711$ and epileptic and myoclonic phenomena in the first three days ${ }^{33}$ after cardiopulmonary resuscitation were confirmed to be the single most sensitive clinical predictors of bad outcome. However, a few patients with these findings enjoyed a good outcome, both in our series and previous ones. ${ }^{123436}$ For this reason we think that the use of a combination of clinical signs (for example, GCS), should be preferred to using a single clinical parameter for prognostication of postanoxic coma. Prognostically unfavourable SEPs and EEG were found both in $40 \%-50 \%$ of patients with bad outcome. The lower than expected EEG sensitivity for severe brain damage may be in part related to the fact that we included $\alpha$ coma patterns in the uncertain rather than unfavourable EEG signs. This decision was prompted by a few reports (confirmed in this study) of patients with $\alpha$ coma and good outcome. ${ }^{18253237}$ Although SEP and EEG have a similar sensitivity in detecting severe postanoxic brain damage, and the EEG may help in the recognition of subclinical seizure activity, we think that SEP should be preferred for prognostication in coma after cardiac arrest; SEPs are faster to perform and easier to interpret, and also they are not influenced by sedating medications. Also, we found that EEG only rarely added prognostic information when clinical examination and SEP results were considered together. Although we confirmed previous reports that over $80 \%$ of patients with raised serum neuron specific enolase and decreased ionised calcium have a bad outcome, ${ }^{2326}$ the limited number of patients evaluated in this and previous studies and the non-negligible percentage of false pessimistic predictions call for caution. The determination of CSF enzymes, including creatine kinase, may yield a higher sensitivity and specificity in predicting outcome after cardiac arrest. None of these biochemical tests can, however, be suggested for routine use at the present time. ${ }^{38}$

MULTIVARIATE PROGNOSIS OF BAD OUTCOME In this, as well as previous reports the univariate application of selective criteria allowed the identification of only about $50 \%$ of the patients with bad outcome. ${ }^{367}$ Therefore, the most relevant result of this study is the increase in the percentage of correct predictions of bad outcome from $58 \%$ with clinical examination alone to $77 \%$ with the combination of clinical examination and electrophysiology. In other words, the recording of SEP and EEG allowed the prediction of outcome in one third of those patients, in whom clinical signs alone were not (yet) conclusive. In addition, unfavourable electrophysiological parameters supported the clinical assessment in predicting a bad outcome in two thirds of patients with unfavourable clinical signs. It is of clinical relevance to point out that the utility of electrophysiological recordings applied not only to patients who died within the first three days but also to those who survived longer. Conversely, in the 16 patients tested, biochemical tests were of no additional prognostic help. A multivariate logistic regression analysis of our data identified the association of a GCS $<8$ at 48 hours with an abnormal or absent SEP as highly predictive of a bad outcome (risk 97\%, 95\% CI 86\%-99\%). This means that the combination of clinical signs and SEPs may allow the application of less selective prognostic criteria for prognostication of bad outcome than those suggested when these variables are used in isolation (table 2). There have been only a few studies assessing the prognostic value of a multivariate approach and none including clinical examination, EEG, SEP, and biochemical parameters. Edgren $e t a l^{25}$ correctly predicted the outcome in about $75 \%$ of 32 patients combining a modified GCS at 48 hours with the EEG at 48 hours, and the CSF lactate at 24 hours. In that study, however, the percentage of false pessimistic predictions was as high as $29 \%$. In a study of 40 patients, Rothstein et al found, as we did, that SEPs were more reliable than EEG in predicting outcome. These authors did not consider, however, any clinical parameter, and the exact timing of electrophysiological recordings was not specified. Becker et 
al performed repeated clinical examination, EEG, SEP, and proton magnetic resonance spectroscopy (MRS) in a series of 25 patients with postanoxic coma. ${ }^{29}$ Demonstration of brain lactate in MRS and absent cortical SEPs were found to be reliable predictors of bad outcome. The limitations of this study were the high cardiac mortality, which reduced the number of patients available for analysis of cerebral prognosis, and the lack of analysis of the prognostic value of clinical examination and EEG.

The accuracy of the multivariate approach used in this study needs to be verified in a larger group of patients before it can be adopted in clinical practice. Nevertheless, the following approach to prognostication after cardiac arrest can be suggested integrating our data with the information available in the literature. In the first 48 hours after cardiopulmonary resuscitation serial clinical examination including assessment of brainstem reflexes and GCS should be performed. Electrophysiological testing need not be considered in the first 24 hours, unless status epilepticus or status myoclonicus are suspected. If by 24-48 hours the patient does not awaken, SEPs should be recorded. If clinical examination and SEPs are prognostically nonconclusive an EEG could be performed. We think that the combination of GCS at 48 hours, SEPs, and, when necessary, EEG can assist the clinician in predicting the outcome of coma after cardiac arrest with reasonable accuracy. As any available prognostic model in postanoxic coma carries some risk of error, ${ }^{13}$ the limitation or withdrawal of medical treatment should always be made on an individual basis, involving the patient's family in the decision and considering medical as well as psychosocial issues.

Dr G van Melle, Department of Statistics, University Hospital, Lausanne, Switzerland, helped with the statistical analysis. Drs $T$ Herren and $T$ Weiss, Department of Internal Medicine, University Hospital, Bern, Switzerland, collaborated in the recruitment and care of the patients. The measurement of the serum neuron specific enolase was performed by Dr P Huber, Gynecological Laboratory Medicine, University Hospital, Basel, Switzerland, and that of the serum ionised calcium by Dr E Peheim, Chemisches Zentrallabor, University Hospital, Dr E Peheim, Chemisches Zentrallabor, University Hospital,
Bern, Switzerland. Dr F Glocker and Mrs J Schmid assisted in the recording of SEPs. Drs I Drury and D Gelb, Department of the recording of SEPs. Drs I Drury and D Gelb, Department of USA, made helpful comments.

1 Bedell SE, Delbanco TL, Cook EF, Epstein FH. Survival after cardiopulmonary resuscitation in the hospital. $N$ Engl f Med 1983;309:569-76.

2 Longstreth WT, Diehr P, Inui TS. Prediction of awakening after out-of-hospital cardiac arrest. $N$ Engl $f M e d$ 1983:308:1378-82.

3 Levy DE, Caronna JJ, Singer BH, et al. Predicting the outcome from hypoxic-ischemic coma. $\mathcal{F} A M A$ 1985;254 1171

4 Gray WA, Capone RJ, Most AS. Unsuccessful emergency medical resuscitation-Are continued efforts in the emergency department justified? $N$ Engl $f$ Med 1991;325: 1393-8.

5 Jörgensen EO. Natural history of global and critical brain ischemia. Resuscitation 1981;9:131-88.

6 Mullie A, Buylaert W, Michem N, et al. Predictive value of Glasgow coma score for awakening after out-of-hospital cardiac arrest. Lancet 1988;137-40.
7 Edgren E, Hedstrand U, Kelsey S, Sutton-Tyrell K, Safar $P$ and BRCT I Study Group. Assessment of neurological prognosis in comatose survivors of cardiac arrest. Lancet prognosis in comatos

8 Earnest MP, Breckenridge JC, Yarnell PR, Oliva PB. Quality of survival after out-of hospital cardiac arrest: predictive value of early neurologic evaluation. Neurology 1979;29:56-60.

9 Snyder BD, Gumnit RJ, Leppik IE. Neurologic prognosis after cardiopulmonary arrest: IV. Brainstem reflexes. Neurology 1981;31:1092-7.

10 Longstreth WT, Inui TS, Cobb LA, Copass MK. Neurologic recovery after out-of-hospital cardiac arrest. Ann Intern Med 1983;98:588-92.

11 Hamel MB, Goldman L, Teno J, et al. Identification of comatose patients at high risk for death or severe disabilcomatose patients at high risk
ity. $\mathcal{F} A M A$ 1995;273:1842-8.

12 Golby A, McGuire D, Bayne L. Unexpected recovery from anoxic-ischemic coma. Neurology 1995;45:1629-30.

13 Shewmon DA, De Giorgio CM. Early prognosis in anoxic coma. Neurol Clin 1989;7:823-43.

14 Bates D. Defining prognosis in medical coma. $f$ Neurol Neurosurg Psychiatry 1991;54:569-71.

15 Sacco RL, Van Gool R, Mohr JP, et al. Non traumatic coma. Glasgow coma score and coma etiology as predictors of 2-week outcome. Arch Neurol 1990;47:1181-4.

$16 \mathrm{Madl}$ C, Grimm G, Kramer L, et al. Early prediction of individual outcome after cardiopulmonary resuscitation. Lancet 1993;341:855-60.

17 Prior. The EEG in acute cerebral anoxia. Amsterdam: Excerpta Medica, 1973.

18 Bassetti C, Karbowski K. Prognostischer Wert der Elektroenzephalographie bei nicht-traumatischen Elektroenzephalographie bei nicht-traum

19 Synek VM. Value of a revised EEG coma scale for prognosis after cerebral anoxia and diffuse head injury. Clin Electroencephalogr 1990;21:25-30.

20 Walser H, Mattle H, Keller HM, Janzer R. Early cortical median nerve somatosensory evoked potentials. Prognostic value in anoxic coma. Arch Neurol 1986;42: 32-8.

21 Brunko E, Zegers de Beyl D. Prognostic value of early cortical somatosensory evoked potentials after resuscitation from cardiac arrest. Electroencephalogr Clin Neurophysiol 1987;66:15-24.

22 Rothstein TL, Thomas EM, Sumi SM. Predicting outcome in hypoxic-ischemic coma. A prospective clinical and
electrophysiological study. Electroencephalogr Clin electrophysiological study.

23 Urban P, Scheidegger D, Buchmann B, Barth D. Cardiac arrest and blood ionized calcium levels. Ann Intern Med 1988;109:110-3

24 Longstreth WT, Clayson KJ, Sumi SM. Cerebrospinal fluid and serum creatine kinase BB activity after out-ofhospital cardiac arrest. Neurology 1981;31:455-8.

25 Edgren $E$, Hedstrand $U$, Nordin $M$, et al. Prediction of outcome after cardiac arrest. Crit Care Med 1987;15:820-5.

26 Roine RO, Somer H, Kaste M, Viinikka L, Karonen S. Neurological outcome after out of hospital cardiac arrest: prediction by cerebrospinal fluid enzyme analysis. Arch Neurol 1989;46:753-6.

27 Jörgensen EO. EEG without detectable cortical activity and cranial nerve areflexia as parameters of brain death. cranial nerve areflexia as parameters of brain
Electroencephalogr Clin Neurophysiol 1974;36:70-5.

28 Bassetti C, Mathis J, Hess CW. Multimodal electrophysiological studies including motor evoked potentials in patients with locked-in syndrome: report of six patients. $\mathcal{F}$ Neurol Neurosurg Psychiatry 1994;57:1403-6.

29 Berek K, Lechleitner P, Luef G, et al. Early determination of neurologic outcome after prehospital cardiopulmonary resuscitation. Stroke 1995;26:543-9.

30 Scollo-Lavizzari G, Bassetti C. Prognostic value of the EEG in post-anoxic coma after cardiac arrest. Europ Neurol 1987;26:161-70.

31 Brendler SJ, Selverstone B. Recovery from decerebration. Brain 1970;93:381-92.

32 Austin E, Wilkus RJ, Longstreth WT. Etiology and prognosis of alpha coma. Neurology 1988;33:773-7.

33 Wijdicks EFM, Parisi JE, Sharbrough FW. Prognostic value of myoclonus status in comatose survivors of carvalue of myoclonus status in comatose

34 Celesia GG, Grigg MM, Ross E. Generalized status myoclonicus in acute anoxic and toxic-metabolic encephalopathies. Arch Neurol 1988;45:781-4

35 Krumholz A, Stern BJ, Weiss HD. Outcome from coma after CPR: relation to seizures and myoclonus. Neurology 1988;38:401-5.

36 Arnoldus EPJ, Lammers GJ. Potsanoxic coma: good recovery despite myoclonic status. Ann Neurol 1995;38:697-8.

37 Soerensen K, Thomassen A, Wernberg M. Prognostic significance of alpha frequency EEG rhythm in coma after cardiac arrest. $\mathcal{f}$ Neurol Neurosurg Psychiatry 1978;41: 840-2.

38 Longstreth WT. Neurologic complications of cardiac arrest. In: Aminoff A, ed. Neurology and general medicine, 2 nd ed. Edinburgh: Churchill-Livingstone, 1994:159-82. 